\title{
Quercetin reverses TNF- $\alpha$ induced osteogenic damage to human periodontal ligament stem cells by suppressing the NF-кB/NLRP3 inflammasome pathway
}

\author{
WENJING ZHANG $^{1,2}$, LINGLU JIA $^{1,2}$, BIN ZHAO $^{1,2}$, YIXUAN XIONG $^{1,2}$, \\ YA-NAN WANG ${ }^{1,2}$, JIN LIANG $^{3}$ and XIN XU ${ }^{1,2}$ \\ ${ }^{1}$ School of Stomatology, Shandong University; ${ }^{2}$ Shandong Provincial Key Laboratory of Oral Tissue Regeneration, \\ School of Stomatology, Shandong University, Jinan, Shandong 250012; ${ }^{3}$ School of Stomatology, \\ Shandong First Medical University and Shandong Academy of Medical Sciences, Jinan, Shandong 250117, P.R. China
}

Received October 16, 2020; Accepted January 21, 2021

DOI: $10.3892 / \mathrm{ijmm} .2021 .4872$

\begin{abstract}
Quercetin (Quer) is a typical antioxidant flavonoid from plants that is involved in bone metabolism, as well as in the progression of inflammatory diseases. Elevated levels of tumor necrosis factor- $\alpha$ (TNF- $\alpha$ ), a typical pro-inflammatory cytokine, can affect osteogenesis. In the present study, TNF- $\alpha$ was used to establish an in vitro model of periodontitis. The effects of Quer on, as well as its potential role in the osteogenic response of human periodontal ligament stem cells (hPDLSCs) under TNF- $\alpha$-induced inflammatory conditions and the underlying mechanisms were then investigated. Within the appropriate concentration range, Quer did not exhibit any cytotoxicity. More importantly, Quer significantly attenuated the TNF- $\alpha$ induced the suppression of osteogenesis-related genes and proteins, alkaline phosphatase (ALP) activity and mineralized matrix in the hPDLSCs. These findings were associated with the fact that Quer inhibited the activation of the NF- $\kappa \mathrm{B}$ signaling pathway, as well as the expression of NLRP3 inflammation-associated proteins in the inflammatory microenvironment. Moreover, the silencing of NLRP3 by small interfering RNA (siRNA) was found to protect the hPDLSCs against TNF- $\alpha$-induced osteogenic damage, which was in accordance with the effects of Quer. On the whole, the present study demonstrates that Quer reduces the impaired osteogenesis of hPDLSCs under TNF- $\alpha$-induced inflammatory
\end{abstract}

Correspondence to: Professor Xin Xu, School of Stomatology, Shandong University, 44-1 Wenhua Xi Road, Jinan, Shandong 250012, P.R. China

E-mail: xinxu@sdu.edu.cn

Dr Jin Liang, School of Stomatology, Shandong First Medical University and Shandong Academy of Medical Sciences, 6699 Qingdao Road, Jinan, Shandong 250117, P.R. China

E-mail: kq1115@163.com

Key words: quercetin, tumor necrosis factor- $\alpha$, human periodontal ligament cells, osteogenesis, NF- $\mathrm{B}$, NLRP3 inflammasome conditions by inhibiting the NF- $\mathrm{B} / \mathrm{NLRP} 3$ inflammasome pathway. Thus, Quer may prove to be a potential remedy against periodontal bone defects.

\section{Introduction}

Periodontitis is a chronic inflammatory disease that can cause irreversible damage to the tissues that support the teeth, such as the periodontal ligament, cementum and alveolar bone, thereby leading to the loss of the affected tooth (1). Due to the importance of the periodontium, periodontal therapy is aimed at suppressing disease progression and promoting the regeneration of the affected periodontal tissue or the structures that support the tooth. Studies have reported the significance of stem cell-based tissue engineering technology in repairing and regenerating damaged tissues and maintaining a highly orderly internal environment (2-4). Human periodontal ligament stem cells (hPDLSCs) are mesenchymal stem cells (MSCs) obtained from human periodontal ligament tissue in a normal or periodontitis environment (5). In vivo and in vitro experiments have verified that hPDLSCs have good proliferative, self-renewal and multidirectional differentiation potentials $(6,7)$. The osteogenic differentiation ability of hPDLSCs is superior to that of other odontogenic stem cells, such as dental pulp cells, gingival mesenchymal stem cells and dental follicle stem cells $(8,9)$. However, the biological behavior of stem cells is closely associated with the tissue microenvironment. For instance, an inflammatory microenvironment may alter the differentiation ability of stem cells, and weaken their osteogenic differentiation and tissue regeneration ability $(5,10)$. Therefore, an effective strategy is required to modulate the differentiation potential of hPDLSCs during inflammation.

Tumor necrosis factor- $\alpha(\mathrm{TNF}-\alpha)$ is the main regulator of several pro-inflammatory cytokines, including interleukin (IL)-1 $\beta$ and IL- 6 that are released by monocytes and macrophages, as well as by endothelial cells in periodontitis (11). It is associated with osteoclastogenesis, the absorption of alveolar bone and the inhibition of osteogenesis.

Nuclear factor (NF)- $\kappa \mathrm{B}$ is an important nuclear transcription factor that regulates cell apoptosis, inflammatory responses 
and osteoblast differentiation. Elevated TNF- $\alpha$ levels negatively affect the osteogenic differentiation of mesenchymal stem cells via the activation of the NF- $\kappa \mathrm{B}$ signaling pathway when it binds its receptor $(12,13)$. Moreover, $\mathrm{NF}-\kappa \mathrm{B}$ is a priming signal for the activation of the NOD-like receptor family pyrin domain-containing protein 3 (NLRP3) inflammasome that is involved in the expression of NLRP3 protein (14). The NLRP3 inflammasome is a protein complex composed of a receptor protein (NLRP3), adaptor protein (ASC) and effector protein (procaspase-1). It plays a vital role in the innate immunity of infections, inflammatory and chronic diseases, such as Alzheimer's disease, type 2 diabetes and osteoporosis (15). The assembly of the NLRP3 inflammasome, followed by the activation of caspase-1, and the maturation of IL-1 $\beta$ and IL-18, trigger an inflammatory cascade response (16). Advanced glycation end products significantly upregulate the expression of NLRP3 in hPDLSCs through the NF- $\kappa \mathrm{B}$ signaling pathway (17). Studies have demonstrated that NLRP3 activation increases adipogenesis and inhibits the osteogenesis of human umbilical cord stem cells, while the silencing of NLRP3 alleviates estrogen depletion-induced osteoporosis in mice $(18,19)$. Most importantly, previous clinical studies have reported that gene polymorphisms of NLRP3 are associated with susceptibility to periodontitis and the expression levels of NLRP3 inflammasome-associated proteins are particularly enhanced in periodontitis $(20,21)$. However, whether NLRP3 associates with $\mathrm{NF}-\kappa \mathrm{B}$ to inhibit the osteogenic differentiation of hPDLSCs needs to be elucidated in a model of TNF- $\alpha$-induced periodontitis.

Quercetin (Quer; 3,3',4',5,7-pentahydroxyflavone), a flavonoid derived from common vegetables and fruits, such as apples, onions and blueberries, is known to exhibit antitumor, anti-inflammatory and antioxidant properties (22). Quer has been reported to reduce periodontitis damage in rats and to improve the osteogenic differentiation abilities of bone marrow-derived MSCs (BMMCs) during inflammation to alleviate osteoporosis symptoms $(23,24)$. Furthermore, it has been demonstrated that Quer can reverse lipopolysaccharide (LPS)-induced osteoblast apoptosis and restore the impaired osteogenic differentiation ability of MC3T3-E1 cells (25). However, it has not yet been established whether Quer reduces osteogenic damage to hPDLSCs during TNF- $\alpha$-induced inflammation. It has also been shown that Quer decreases osteoclast formation by inhibiting IL-17-induced receptor activator of nuclear factor $\kappa \mathrm{B}$ ligand (RANKL) expression and inhibits bone resorption in rheumatoid arthritis via the suppression of $\mathrm{NF}-\kappa \mathrm{B}$ (26). Recent studies based on rat models in vivo, have demonstrated that Quer treatment reduces NLRP3 inflammasome-related protein expression and inflammatory cytokine levels $(27,28)$. In addition, Quer has been shown to exert protective effects against endoplasmic reticulum stress-related endothelial cell damage and isoniazid-induced L02 cell apoptosis by suppressing NLRP3 inflammasome activation $(29,30)$.

Based on these findings, it was hypothesized that Quer could attenuate the suppression of the osteogenic differentiation of hPDLSCs in TNF- $\alpha$-induced inflammation and that the underlying mechanisms may be associated with the $\mathrm{NF}-\kappa \mathrm{B} / \mathrm{NLRP} 3$ inflammasome pathway.

\section{Materials and methods}

Cells and cell culture. The approval for the present study was provided by the Committee on Ethics of the Stomatology Hospital of Shandong University (protocol no. GR201806). From April, 2019 to September, 2019, freshly extracted teeth were collected from orthodontic volunteers aged 16-22 years at the Stomatology Hospital of Shandong University. All participants provided signed informed consent in accordance with the Helsinki Declaration. The method of hPDLSC isolation from teeth was similar to a previously reported one (31). Briefly, the extracted teeth were placed in a $15 \mathrm{ml}$ centrifuge tube with $\alpha$-MEM (Biological Industries) amended with 5\% antibiotics $(100 \mathrm{U} / \mathrm{ml}$ penicillin, $10 \mathrm{mg} / \mathrm{ml}$ streptomycin) on ice. They were transferred to an ultra-clean workbench as soon as possible for use in further experiments. Each tooth was washed thrice in phosphate-buffered saline (PBS; Biological Industries) containing 5\% antibiotics. Periodontal ligament tissue from the middle third of the root surface was gently scraped with a sterile surgical blade and cut into tiny fragments, which were then seeded into culture dishes $(25 \mathrm{~cm})$. hPDLSCs were grown at $37^{\circ} \mathrm{C}$ in medium supplemented with $\alpha$-MEM, $20 \%$ fetal bovine serum (FBS; Biological Industries) and $1 \%$ antibiotics in a $5 \% \mathrm{CO}_{2}$ incubator. Following inoculation 3-4 h, the culture dish $(25 \mathrm{~cm})$ was turned over to ensure that the hPDLSCs touched the culture medium. The medium was refreshed after every 3 days until the cells grew out from the tissue sections. The cells were passaged at $80-90 \%$ confluence and the cells at passages 3 to 5 were used for further experiments.

Colony-forming assay. The hPDLSCs were cultured in a 10 -cm diameter culture plate (1,000 cells per plate) in $\alpha$-MEM supplemented with 10\% FBS [common medium (CM)]. After 7 days, the hPDLSCs were rinsed thrice using PBS, then fixed in $4 \%$ polyformaldehyde, after which they were stained with $0.1 \%$ crystal violet (Beijing Solarbio Science \& Technology Co., Ltd.) at room temperature for $15 \mathrm{~min}$. The cell clones were observed under a microscope (Olympus Corp.), and aggregates of $>3 \mathrm{~mm}$ were considered as clones.

Flow cytometric analysis of hPDLSC surface marker phenotypes. Passage 3 cells were digested using trypsin, followed by washing using PBS. A total of $100 \mu \mathrm{l}$ of prepared cell suspension was then incubated with antibodies (FITC mouse anti-human CD90, $5 \mu$ l, PE mouse anti-human CD44, $5 \mu 1$, PerCP-Cy ${ }^{\mathrm{TM}} 5.5$ mouse anti-human CD105, $5 \mu \mathrm{l}$, APC mouse anti-human CD73, $5 \mu$, PE hMSC isotype control negative cocktail, $20 \mu \mathrm{l}$, PE hMSC negative cocktail, $20 \mu \mathrm{l}$, hMSC isotype control positive cocktail, $20 \mu \mathrm{l}$, hMSC positive cocktail, $20 \mu 1$, \#562245, BD Biosciences) conjugated with a monoclonal fluorescent dye in the dark for $20 \mathrm{~min}$ at $4^{\circ} \mathrm{C}$. Cells were detected using flow cytometry, as per the manufacturer's protocol (\#660519, BD Biosciences). The MSC-associated positive cocktail, including CD105-PerCP-Cy, CD73-APC, CD44-PE, CD90-FITC and MSC-associated negative cocktail that included CD34 PE, CD45 PE, CD19 PE, HLA-DR PE and CD11b PE (\#562245, BD Biosciences) were used. Respective negative and positive isotype control cocktails were used as 
systemic controls. Final database analysis was carried out using FlowJo software (Beckman coulter, Inc.).

Multi-lineage differentiation assays of hPDLSCs. The hPDLSCs were incubated in 6-well dishes at $1 \times 10^{5}$ cells/well with CM. At $80-90 \%$ density, the corresponding culture medium was replaced to examined osteogenesis and adipogenesis.

For osteogenesis, cells were exposed to an osteogenic induction medium (OIM) containing $\alpha$-MEM with $10 \% \mathrm{FBS}$, $\beta$-glycerophosphate $(10 \mathrm{mM})$, dexamethasone $(10 \mathrm{nM})$ and ascorbic acid (50 mg/l; Beijing Solarbio Science \& Technology Co., Ltd.) for 21 days. The cells were then incubated with Alizarin Red solution (Sigma-Aldrich; Merck KGaA) at $22^{\circ} \mathrm{C}$ for $10 \mathrm{~min}$ to observe the mineralization.

For adipogenesis, cells were treated in an adipogenic induction medium containing $\alpha$-MEM with $10 \% \mathrm{FBS}$, insulin $(10 \mathrm{mg} / \mathrm{l})$, dexamethasone $(1 \mu \mathrm{M})$, indomethacin $(0.2 \mathrm{mM})$ and isobutyl-methylxanthine $(0.5 \mathrm{mM}$; Beijing Solarbio Science \& Technology Co., Ltd.) for 28 days. Subsequently, the hPDLSCs were incubated with Oil Red O solution at $22^{\circ} \mathrm{C}$ for $20 \mathrm{~min}$ to observe lipid droplets.

Cell proliferation assay. According to the manufacturer's instructions, the cell counting kit-8 (CCK-8; MedChemexpress Co., Ltd.) kit was utilized to detect the proliferative ability of hPDLSCs. A total of 4,000 cells/well were plated in a 96-well plate and cultured at $37^{\circ} \mathrm{C}$ for $24 \mathrm{~h}$ with CM. The hPDLSCs were then subjected to various concentrations $(0$, $0.01,0.1,1,5,10,50$ and $100 \mu \mathrm{M}$ ) of Quer (Beijing Solarbio Science \& Technology Co., Ltd.) for 3 days. Cell viability was examined at 24, 48 and $72 \mathrm{~h}$. Moreover, the hPDLSCs were stimulated with various concentrations $(0,1,10,20,30$, $50 \mathrm{ng} / \mathrm{ml}$ ) of TNF- $\alpha$ (cat. no. 300-01A Peprotech Inc.) for 4 days. CCK-8 reagent $(10 \mu \mathrm{l})$ was mixed with $90 \mu$ l complete culture medium per well and incubated at $37^{\circ} \mathrm{C}$ with the cells $1 \mathrm{~h}$ later. The absorbance at $450 \mathrm{~nm}$ was measured with the SPECTROstar plate reader (BMG Labtech Inc.).

Alkaline phosphatase (ALP) activity and ALP staining assay. Following 7 days of osteogenesis, the ALP activity of the cells was assessed using the ALP activity kit (Nanjing Jiancheng Bioengineering Institute) as per the producer's protocols. For ALP staining, the hPDLSCs were fixed in paraformaldehyde (4\%), then stained with an ALP staining kit (Beyotime Institute of Biotechnology) at room temperature for 10 min after 7 days. Cells were observed and examined using an inverted microscope (Olympus Corp.).

Alizarin Red staining (ARS) assay. Following 21 days of osteogenic induction, the cells were rinsed 3 times then fixed in paraformaldehyde (4\%), after which they were stained using an Alizarin Red solution (Beijing Solarbio Science \& Technology Co., Ltd.) for $10 \mathrm{~min}$ at $22^{\circ} \mathrm{C}$.

Gene expression analysis. TRIzol reagent (Qingdao Haosail Science \& Technology Co., Ltd.) was utilized to isolate total RNA from cells as per producer's suggestions. Subsequently, $1 \mu \mathrm{g}$ RNA was reverse transcribed as the template strand using the HiScript ${ }^{\circledR}$ III Reverse Transcriptase kit (\#R323-01,
Nanjing Vazyme Biotech Co., Ltd.) to obtain cDNA. RT-qPCR was performed by The Roche Light Cycler $^{\circledR} 480 \mathrm{II}$ in a $10 \mu \mathrm{l}$ reaction volume with the SYBR qPCR Master Mix (Nanjing Vazyme Biotech Co., Ltd.). The PCR cycling conditions were as follows: Initial denaturation at $95^{\circ} \mathrm{C}$ for $30 \mathrm{sec}$ followed by 45 cycles of denaturation at $95^{\circ} \mathrm{C}$ for $5 \mathrm{sec}$ and annealing $65^{\circ} \mathrm{C}$ for $30 \mathrm{sec}$. Changes in target gene expression were calculated using the $2^{-\Delta \Delta C q}$ method (32). The primers used in this assay were as follows: GAPDH forward, 5'-GCACCGTCAAGG CTGAGAAC-3' and reverse, 5'-TGGTGAAGACGCCAGTGG AALP-3'; collagen I (COL1) forward, 5'-GCTGATGATGCC AATGTGGTT-3' and reverse, 5'-CCAGTCAGAGTGGCA CATCTTG-3'; ALP forward, 5'-GTGAACCGCAACTGG TACTC-3' and reverse, 5'-GAGCTGCGTAGCGATGTCC-3'; runt-related transcription factor 2 (RUNX2) forward, 5'-GTT TCACCTTGACCATAACCGT-3' and reverse, 5'-GGGACA CCTACTCTCATACTGG-3'; NLRP3 forward, 5'-ACGACT GCGTCTCATCAAGG-3' and reverse, 5'-CATCGGGGT CAAACAGCAAC-3'; caspase-1 forward, 5'-GTGCAGGAC AACCCAGCTAT-3' and reverse, 5'-TGCGGCTTGACTTGT CCATT-3'; IL-1 $\beta$ forward, 5'-GTACCTGTCCTGCGTGTT GA-3' and reverse, 5'-GGGAACTGGGCAGACTCAAA-3'; IL-6 forward, 5'-CCTTCGGTCCAGTTGCCTTCT-3' and reverse, 5'-CAGTGCCTCTTTGCTGCTTTC-3'.

Western blot analysis. Proteins were extracted from the cells as previously described (7). Briefly, the hPDLSCs were rinsed in PBS, then lysed on ice in RIPA buffer (Beijing Solarbio Science \& Technology Co., Ltd.) comprising 1\% phosphatase inhibitor (Boster Biological Technology Co., Ltd.) plus 1\% PMSF (Beijing Solarbio Science \& Technology Co., Ltd.). Following ultrasonic cracking and centrifugation $\left(12,000 \mathrm{x} \mathrm{g} ; 20 \mathrm{~min} ; 4^{\circ} \mathrm{C}\right)$, the concentration of proteins was determine using the BCA assay kit (Beijing Solarbio Science \& Technology Co., Ltd.). Subsequently, the proteins from different groups were resolved on 10\% SDS-PAGE and transferred onto a PVDF membrane. A total of $20 \mu \mathrm{g}$ proteins from different groups were loaded on $10 \%$ SDS-PAGE and separated through electrophoresis. Subsequently, the separated proteins were eletro-blotted onto a PVDF membrane. Blocking was performed using 5\% non-fat dry milk at $22^{\circ} \mathrm{C}$ for $1 \mathrm{~h}$, then probed with rabbit anti-human GAPDH polyclonal (1:20,000, cat. no. 10494-1-AP; ProteinTech Group, Inc.), rabbit anti-human RUNX2 monoclonal (1:1,000, cat. no. ab23981; Abcam), rabbit anti human-COL1 monoclonal (1:1,000, cat. no. \#84336; Cell Signaling Technology, Inc.), rabbit anti human-ALP monoclonal (1:5,000, cat. no. ab108337; Abcam), rabbit anti human-NLRP3 polyclonal (1:1,000, cat. no. WL02635; Wanlei Biotech Co., Ltd.), rabbit anti human-procaspase-1 polyclonal (1:500, cat. no. WL02996; Wanlei Biotech Co., Ltd., China), rabbit anti human-caspase-1 polyclonal (1:500, cat. no. WL03450; Wanlei Biotech Co., Ltd.), rabbit anti human-phosphorylated (p-)p65 polyclonal (1:500, cat. no. WL02169; Wanlei Biotech Co., Ltd.), rabbit anti human-p-IкB $\alpha$ polyclonal (1:500, cat. no. WL02495; Wanlei Biotech Co., Ltd.), rabbit anti human-IкB $\alpha$ polyclonal (1:500, cat. no. WL01936; Wanlei Biotech Co., Ltd.), rabbit anti human-p65 monoclonal (1:1,000, cat. no. \#59674; Cell Signaling Technology, Inc.) at $4^{\circ} \mathrm{C}$ for $24 \mathrm{~h}$. This was followed by incubation with a horseradish peroxidase-labeled goat 
anti-rabbit IgG secondary antibody (1:20,000, cat. no. 7074S; Santa Cruz Biotechnology, Inc.) at room temperature for $1 \mathrm{~h}$. Protein detection was performed using a chemiluminescent HRP (EMD Millipore) and the expression levels of target proteins were analyzed using Image J $1.47 \mathrm{~V}$ software (National Institutes of Health) and normalized to GAPDH expression.

NLRP3 interfering. The hPDLSCs were seeded into a 6-well plate with CM and transfected with siRNA targeting NLRP3 (si-NLRP3 forward, 5'-CCUCGGUACUCAGCACUAATT-3' and reverse, 5'-UUAGUGCUGAGUACCGAG-3'; $20 \mu \mathrm{M}$ ) or negative control (si-NC forward, 5'-UUCUCCGAACGUGUC ACGUTT-3' and reverse, 5'-ACGUGACACGUUCGGAGA ATT-3'; $20 \mu \mathrm{M}$ ) (Shanghai GenePharma Technology Co., Ltd.) with Micropoly-transfecter ${ }^{\mathrm{TM}}$ cell reagent (\#MT115; Nantong Micropoly Biotech Co., Ltd.) when the cells were at a density of $70-80 \%$. Following $24 \mathrm{~h}$ of treatment, the proteins were extracted to examine the interference efficiency.

Statistical analysis. Data were analyzed using GraphPad Prism, v. 8.0. One-way analysis of variance (ANOVA) was employed to compare data between multiple groups. All post hoc analyses were performed using Tukey's test. The t-test was used to compare data between 2 groups. All tests were carried out in 3 replicates, and data are reported as the means \pm SD A P-value $<0.05$ was considered to indicate a statistically significant difference.

\section{Results}

Cell culture and characterization of hPDLSCs. hPDLSCs were obtained from periodontal ligament tissues by tissue block culture. They were mainly long, fusiform and fibroblast-like cells under an inverted microscope (Fig. 1A). Flow cytometry analysis revealed that passage 3 hPDLSCs positively expressed mesenchymal surface markers (CD90, CD105, CD73 and CD44), and negatively expressed hematopoietic or endothelial-specific markers (CD11b, CD34, CD19, HLA-DR and CD45) (Fig. 1E). Furthermore, the hPDLSCs exhibited their colony formation properties (Fig. 1B). In multi-lineage differentiation potential assays, osteogenic differentiation detected by ARS exhibited mineralized nodules (Fig. 1C), and adipogenic differentiation revealed lipid droplets following staining with Oil Red O solution (Fig. 1D).

Low concentrations of Quer exert a non-toxic effect on hPDLSCs. To evaluate cell viability, CCK-8 assay was performed to determine whether Quer exerts potential cytotoxic effects on the hPDLSCs. It was revealed that Quer did not affect hPDLSC viability at concentrations up to $10 \mu \mathrm{M}$ at 24 and $48 \mathrm{~h}$. However, at high concentrations, such as 50 and $100 \mu \mathrm{M}$, Quer significantly exhibited cellular toxicity against the hPDLSCs at the 3 time points examined (Fig. 2). Therefore, these 2 higher concentrations were excluded from further experiments.

Optimum concentration of Quer exerts a protective effect against hPDLSCs osteogenic damage induced by TNF- $\alpha$. Relative to the control group, various concentrations of TNF- $\alpha$ did not exert an obvious effect on hPDLSC proliferation, as revealed by CCK-8 assay (Fig. 3A). Following osteogenic induction for 7 days, ALP activity revealed that TNF- $\alpha$ concentrations $>20 \mathrm{ng} / \mathrm{ml}$ significantly decreased the hPDLSC osteogenic differentiation ability (Fig. 3B and C). When the hPDLSCs were cultured in OIM, Quer concentrations $>0.01 \mu \mathrm{M}$, particularly those between 1-10 $\mu \mathrm{M}$, reversed the TNF- $\alpha$-induced inhibition of ALP activity (Fig. 3D). Therefore, the $1 \mu \mathrm{M}$ concentration of Quer was used in the subsequent experiments.

Quer inhibits the induction of $I L-1 \beta$ and $I L-6$ induced by $T N F-\alpha$. To investigate the mimicking of the inflammatory environment stimulated by TNF- $\alpha$, the hPDLSCs were stimulated with Quer $(1 \mu \mathrm{M})$, TNF- $\alpha(20 \mathrm{ng} / \mathrm{ml})$, or their combination in CM. RT-qPCR analysis revealed that Quer + TNF- $\alpha$ significantly downregulated the mRNA expression levels of IL-1 $\beta$ and IL- 6 in the hPDLSCs relative to the group stimulated with TNF- $\alpha$ alone. However, Quer alone did not affect the IL- $1 \beta$ and IL-6 gene expression levels (Fig. 4). Therefore, the in vitro inflammatory environment was successfully established, and $1 \mu \mathrm{M}$ Quer had no significant pro-inflammatory effect.

Quer reverses the inhibitory effects of TNF- $\alpha$ on the osteogenic differentiation of hPDLSCs. Osteogenic differentiation was observed in order to ascertain the effects of Quer on osteogenesis under normal conditions or in a TNF- $\alpha$-induced inflammatory microenvironment. Following 7 days of osteogenic induction, western blot analysis revealed that the protein levels of COL1, ALP and RUNX2 were downregulated in the TNF- $\alpha$ group, while the levels of these osteogenic differentiation-related proteins were evidently upregulated following the addition of Quer (Fig. 5A and B). RT-qPCR revealed that the gene expression levels of COL1 and RUNX2 were markedly suppressed in the TNF- $\alpha$ group relative to the control group. However, the suppression of these osteogenesis-associated genes was significantly reversed in the Quer $+\mathrm{TNF}-\alpha$ group (Fig. 5D). Following 7 days of osteogenic induction, ALP activity and ALP staining assay revealed a decreased and improved osteogenic ability of the hPDLSCs in TNF- $\alpha$ group and in the Quer + TNF- $\alpha$ group, respectively (Fig. 5C and E). After 21 days of osteogenic induction, ARS detected more mineralized nodules in the Quer + TNF- $\alpha$ group than in the TNF- $\alpha$ group (Fig. 5F). These findings suggested that Quer reversed the inhibitory effect of TNF- $\alpha$ on the osteogenesis of hPDLSCs.

Quer disrupts the TNF- $\alpha$-induced activation of the $N F-\kappa B / N L R P 3$ inflammasome pathway in hPDLSCs. To clarify the possible mechanisms through which Quer attenuated the TNF- $\alpha$-induced suppression of the osteogenesis of hPDLSCs, the levels of NF-kB pathway-associated proteins and its downstream molecule, NLRP3, were examined by RT-qPCR and western blot analysis. As shown in Fig. 6A and B, the levels of p-p65 and p-IкB $\alpha$ were markedly increased in the TNF- $\alpha$ group compared to the control group. By contrast, the levels of p-p65 and p-IкB $\alpha$ were significantly decreased (Fig. 6A and B) following treatment with Quer. These results revealed that Quer disrupted the NF- $\kappa B$ pathway in the model of TNF- $\alpha$-induced periodontitis. At the same time, western blot analysis was performed to 
A

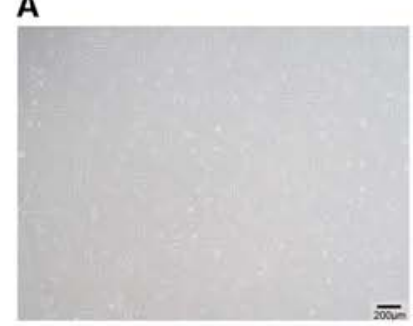

B

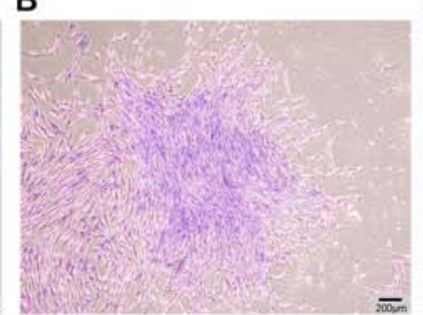

C

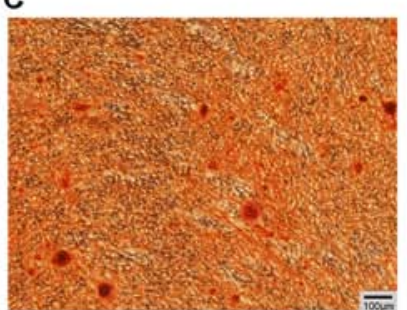

D

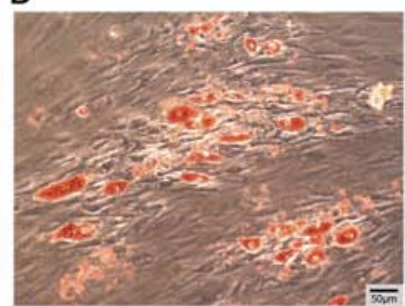

E
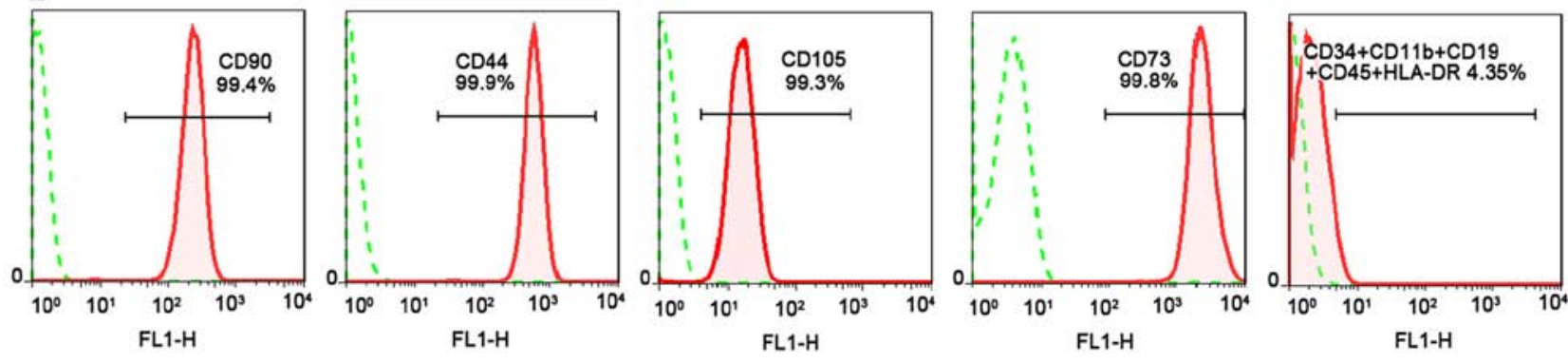

Figure 1. Cell culture and characterization of hPDLSCs. (A) hPDLSCs (P3) displaying spindle fibroblast-like morphology under a phase-contrast microscope (scale bar, $200 \mu \mathrm{m}$ ). (B) Detection of single clones of hPDLSCs (scale bar, $200 \mu \mathrm{m}$ ). (C) Osteogenic differentiation ability of hPDLSCs assayed by ARS (scale bar, $100 \mu \mathrm{m}$ ). (D) Adipogenic differentiation ability of hPDLSCs assayed by Oil Red O staining (scale bar, $50 \mu \mathrm{m}$ ). (E) Negative expression of CD11b, CD34, CD19, CD45 and HLA-DR, and positive expression of CD90, CD105, CD44, and CD73 in hPDLSCs assayed by flow cytometric analysis. hPDLSCs, human periodontal ligament stem cells; P3, passage 3; ARS, Alizarin Red staining.

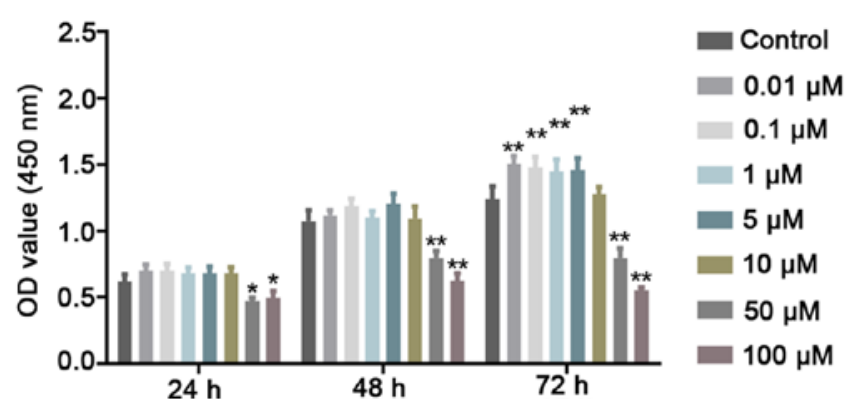

Figure 2. Concentration screening of Quer. hPDLSCs were cultured with various concentrations $(0.01,0.1,1,5,10,50$ and $100 \mu \mathrm{M})$ of Quer for $72 \mathrm{~h}$, and cell viability were examined at 24,48 and $72 \mathrm{~h}$ using the CCK- 8 assay kit. Quer at 50 and $100 \mu \mathrm{M}$ markedly decreased the viability of hPDLSCs at 48 and 72 h. ${ }^{*} \mathrm{P}<0.05$ vs. the control; ${ }^{* *} \mathrm{P}<0.01$ vs. the control. hPDLSCs, human periodontal ligament stem cells; Quer, quercetin.

observe the expression levels of NLRP3, procaspase-1 and caspase-1, which were found to be significantly elevated in the TNF- $\alpha$ group. In the Quer + TNF- $\alpha$ group, the levels of these proteins were found to be downregulated when compared to the TNF- $\alpha$ group (Fig. 6C and D). Additionally, NLRP3 inflammasome-associated gene expression was consistent with the results obtained for protein expression (Fig. 6E). These findings indicated that Quer suppressed the activation of NLRP3 stimulated by TNF- $\alpha$ in hPDLSCs.

Silencing of of NLRP3 reverses TNF- $\alpha$-induced osteogenic damage to hPDLSCs. To explore the effects of NLRP3 protein on TNF- $\alpha$-induced osteogenic damage to hPDLSCs, si-NLRP3 was used to decrease NLRP3 expression. The NLRP3 protein level was markedly decreased in the si-NLRP3, but not in the si-NC group (Fig. 7A). Additionally, the changes in the levels of $\mathrm{NF}-\kappa \mathrm{B}$ signaling pathway-associated proteins were examined following the silencing of NLRP3 in the TNF- $\alpha$-induced inflammatory microenvironment. Western blot analysis revealed that the expression levels of p-p65 and p-IкB $\alpha$ were markedly upregulated in the TNF- $\alpha+$ si-NC group and the TNF- $\alpha+$ si-NLRP3 group. No significant differences were observed between the 2 groups (Fig. 7B and C). That is, the TNF- $\alpha$-induced activation of the NF- $\kappa \mathrm{B}$ signaling pathway was not inhibited by the use of NLRP3 siRNA. hPDLSCs osteogenesis was then induced and the effects of NLRP3 silencing on TNF- $\alpha$-induced osteogenic damage were investigated. After 7 days of osteogenic differentiation, western blot analysis revealed that the levels of osteogenic differentiation-associated proteins, including COL1, ALP and RUNX2 were downregulated in the TNF- $\alpha+$ si-NC group. However, the silencing of of NLRP3 reversed the TNF- $\alpha$-induced inhibition of osteogenic differentiation ability. The effect was consistent with the Quer + TNF- $\alpha+$ si-NC group (Fig. 7D and E). Moreover, RT-qPCR, ALP staining and ALP activity assay revealed a notably upregulated osteogenic ability in the Quer + TNF- $\alpha+$ si-NC or the TNF- $\alpha+$ si-NLRP3 groups, compared to the TNF- $\alpha+$ si-NC group (Fig. 7F-H). Taken together, these results demonstrated that the silencing of NLRP3 protected against TNF- $\alpha$-induced osteogenic damage to hPDLSCs, consistent with the effects of Quer.

\section{Discussion}

Periodontitis is a severe oral disease that results in the defection of periodontal supporting tissue, long-term inflammatory cytokines stimulation, and can cause teeth loss (33). Unlike traditional treatment methods, such as scaling and root planning for periodontitis, tissue regenerative technology, which utilizes combination treatment with drugs and stem cells, has more potential therapeutic properties $(34,35)$. The selected drug should inhibit inflammatory factor secretion, while stem cells have high proliferation and multiple differentiation 

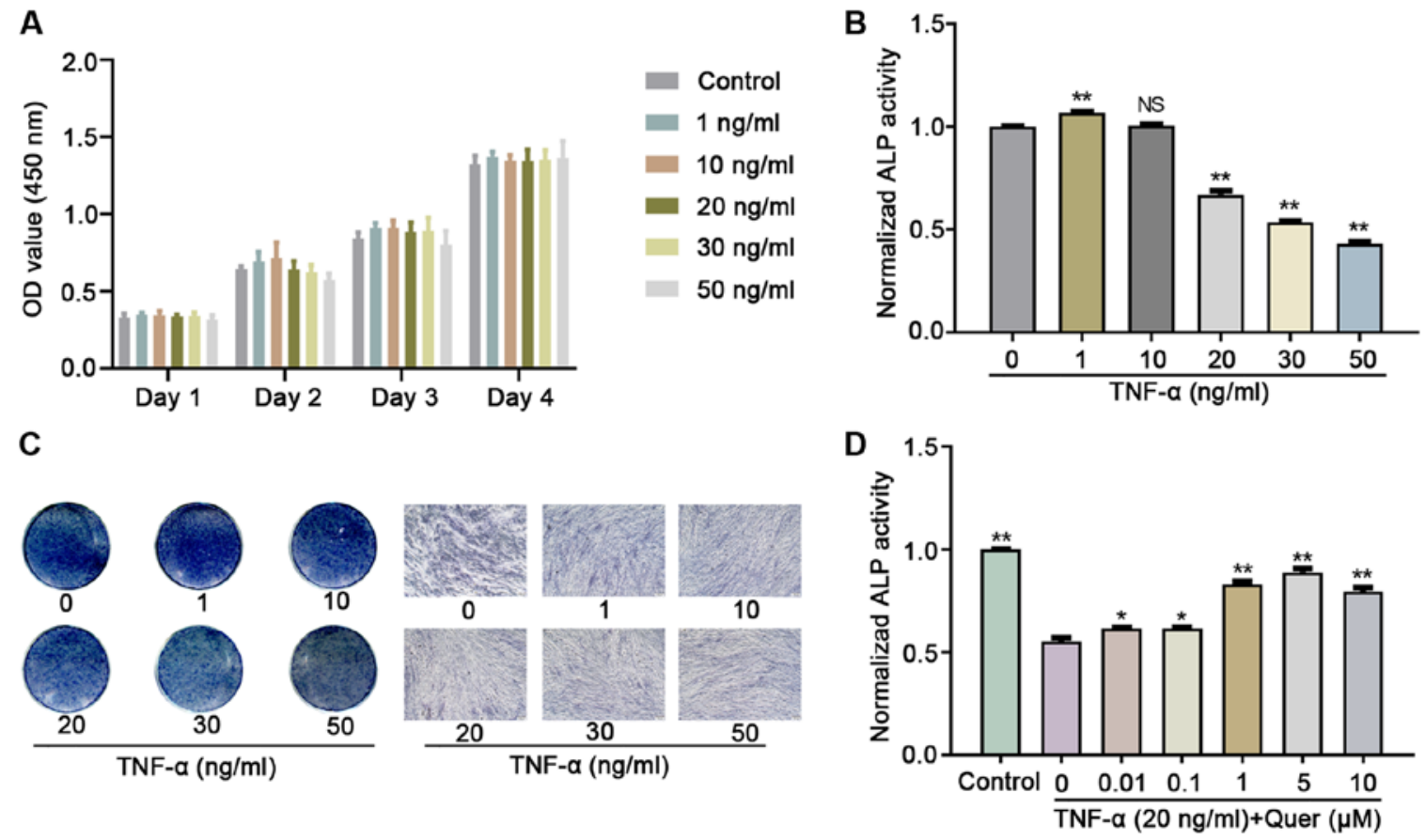

Figure 3. The optimum concentration of Quer exerts a protective effect against TNF- $\alpha$-induced hPDLSC osteogenic damage. (A) hPDLSCs were cultured with various concentrations $(1,10,20,30$ and $50 \mathrm{ng} / \mathrm{ml})$ of TNF- $\alpha$ for 4 days, and cell proliferation was examined on days 1-3 and 4 using the CCK-8 assay kit. (B) hPDLSCs were exposed in OIM with $0,1,10,20,30$ and $50 \mathrm{ng} / \mathrm{ml}$ TNF- $\alpha$, and ALP activity was detected after 7 days. ${ }^{* *} \mathrm{P}<0.01 \mathrm{vs.} \mathrm{the} \mathrm{control,} \mathrm{NS} \mathrm{(no}$ significant difference) vs. control. (C) Illustrative images of ALP staining in OIM with $0,1,10,20,30 \mathrm{and} 50 \mathrm{ng} / \mathrm{ml}$ TNF- $\alpha$ for 7 days (scale bar, $100 \mu \mathrm{m}$ ). (D) hPDLSCs were exposed in OIM containing $20 \mathrm{ng} / \mathrm{ml} \mathrm{TNF-} \alpha$ with various concentrations of Quer $(0,0.01,0.1,1,5$, and $10 \mu \mathrm{M})$, and ALP activity was detected after 7 days. "P<0.05 vs. TNF- $\alpha$ group (without Quer); ${ }^{* *} \mathrm{P}<0.01$ vs. TNF- $\alpha$ group (without Quer). hPDLSCs, human periodontal ligament stem cells; Quer, quercetin; OIM, osteogenic induction medium; TNF- $\alpha$, tumor necrosis factor- $\alpha$; ALP, alkaline phosphatase.
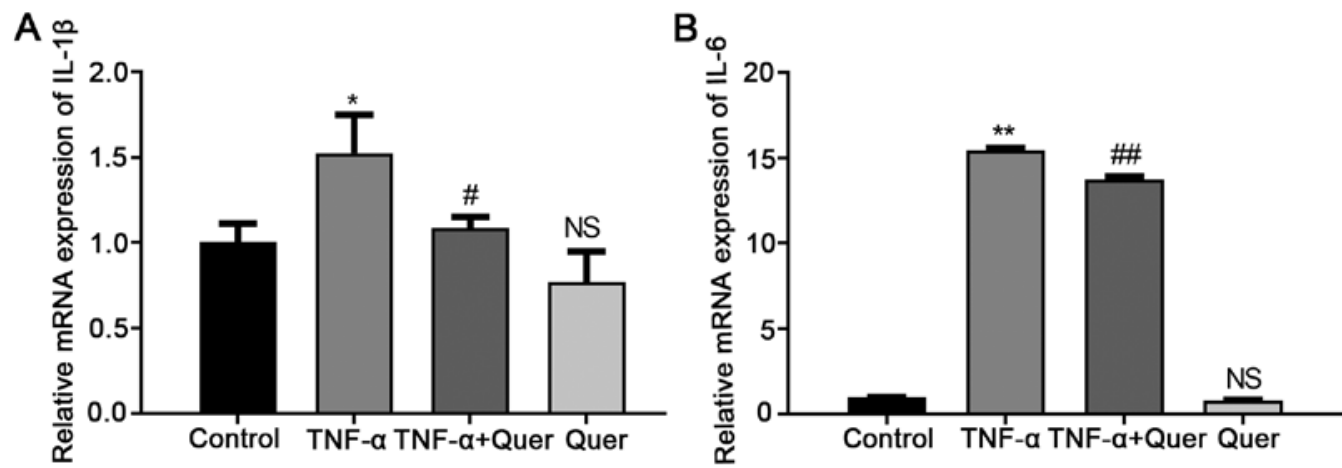

Figure 4. Downregulation of the classical inflammatory cytokines, IL-1 $\beta$ and IL-6, by Quer. Quer $(1 \mu \mathrm{M})$ significantly downregulated the TNF- $\alpha$ $(20 \mathrm{ng} / \mathrm{ml}$ )-induced elevated expression of IL-1 $\beta$ and IL-6 in hPDLSCs. Quer alone did not affect IL-1 $\beta$ and IL-6 mRNA expression levels. (A) mRNA expression level of IL-1 $\beta$ was examined by RT-qPCR. "P<0.05 vs. the control; ${ }^{*} \mathrm{P}<0.05$ vs. TNF- $\alpha$, NS (no significant difference) vs. control. (B) mRNA expression level of IL-6 was detected by RT-qPCR. " $\mathrm{P}<0.01$ vs. the control; ${ }^{\# \#} \mathrm{P}<0.01$ vs. TNF- $\alpha$, NS (no significant difference) vs. control. hPDLSCs, human periodontal ligament stem cells; Quer, quercetin; TNF- $\alpha$, tumor necrosis factor- $\alpha$; IL, interleukin.

potentials to restore the balance of bone formation and resorption for periodontitis therapy. Studies have documented that hPDLSCs have more undifferentiated MSC characteristics and are suitable seed cells for bone tissue regeneration $(6,7)$. In the present study, hPDLSCs were successfully isolated from volunteers with excellent stem cell properties.

The expression of TNF- $\alpha$, as a key pro-inflammatory cytokine, is elevated during periodontal disease progression (36). The overexpression of TNF- $\alpha$ elevates osteoclast activity, resulting in bone destruction and a decreased osteoblast bone formation ability $(37,38)$. As previously reported, various concentrations of TNF- $\alpha$ do not exert an obvious effect on
hPDLSCs proliferation, while elevated concentrations of TNF- $\alpha$ exhibit a negative regulatory effect on osteogenesis (39). The present study found that a TNF- $\alpha$ concentration of $20 \mathrm{ng} / \mathrm{ml}$ was required to mimic an inflammatory microenvironment in vitro, which was demonstrated by decreased ALP staining and ALP activity.

To investigate a novel strategy for alleviating TNF- $\alpha$-induced periodontal supportive tissue destruction, Quer was used. Quer is a natural flavonoid compound that exhibits anti-inflammatory, antioxidant and cardiovascular protective properties at an optimum concentration (40). Quer is a potential candidate for preventing various pathological 

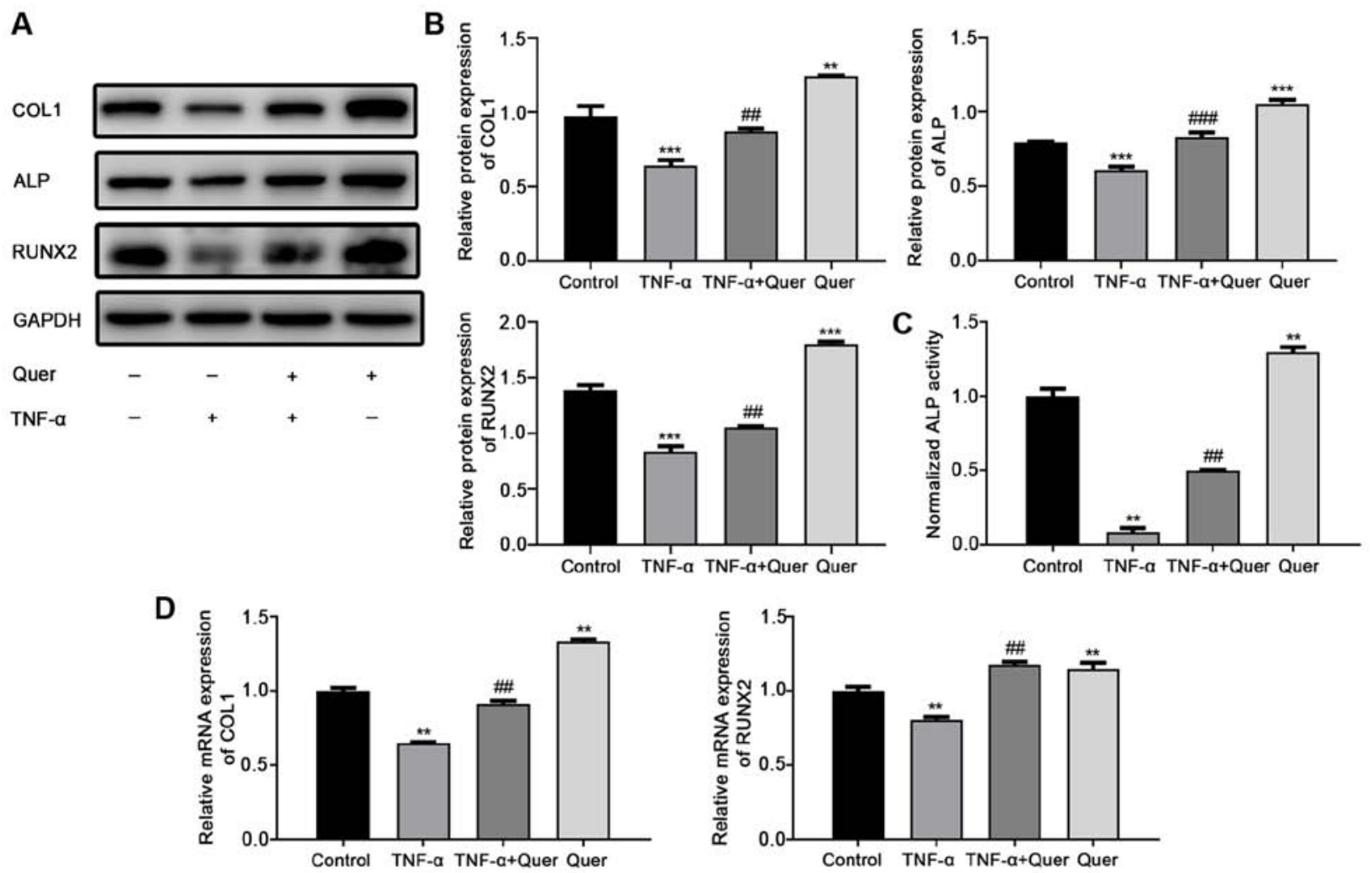

E
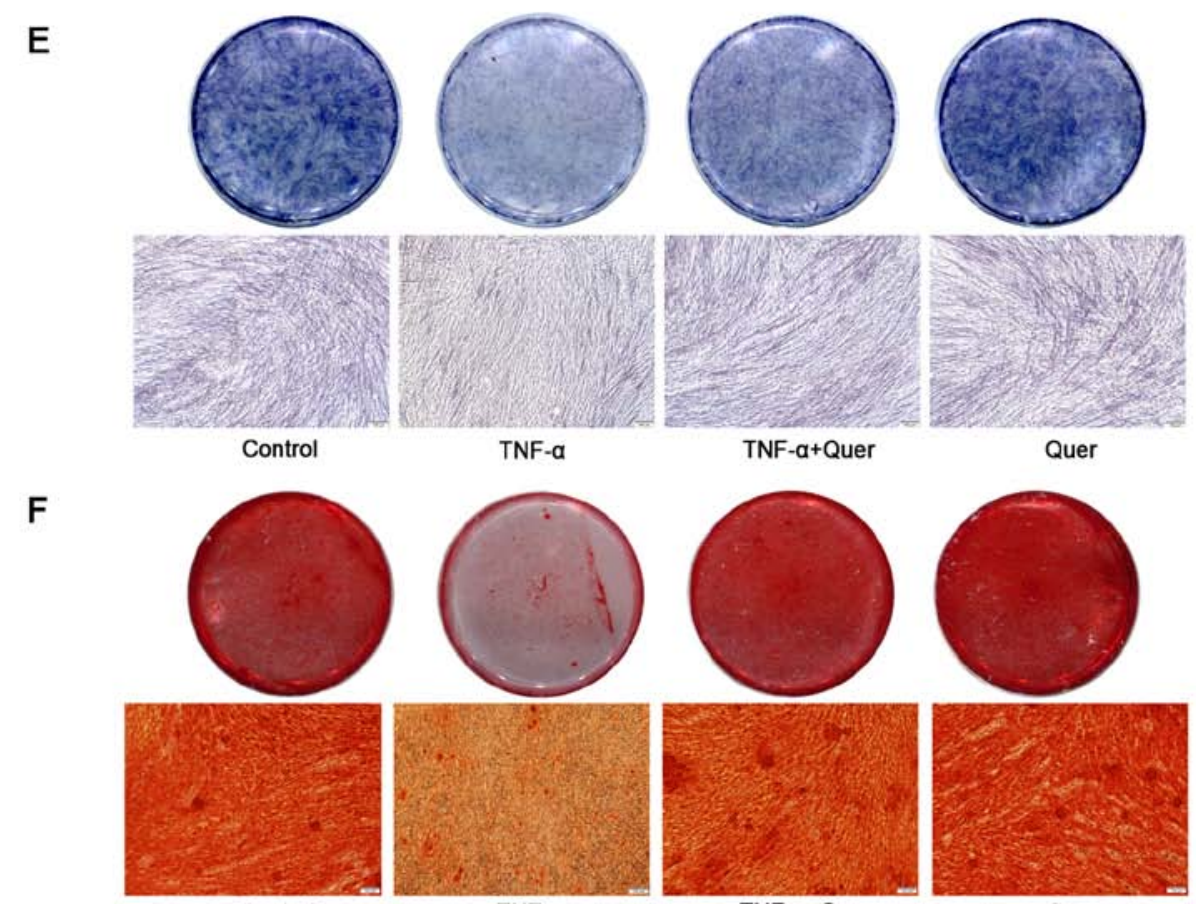

Quer

Control
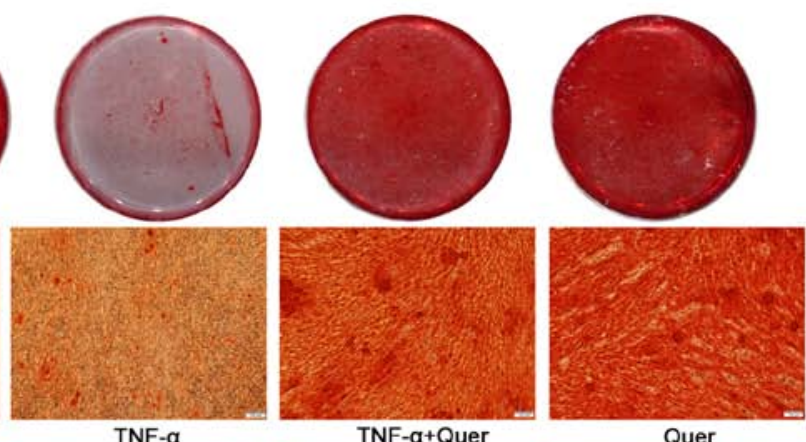

Figure 5. Reversing effect of Quer on TNF- $\alpha$-induced suppression of osteogenesis. hPDLSCs were treated with Quer, TNF- $\alpha$, or their combination for 7 days and/or 21 days in an OIM. (A) Protein levels of COL1, ALP and RUNX2 were measured by western blot analysis on day 7. (B) Band intensities were quantified using ImageJ software. ${ }^{* *} \mathrm{P}<0.01,{ }^{* * *} \mathrm{P}<0.001$ vs. control; ${ }^{\# \#} \mathrm{P}<0.01,{ }^{\# \# \#} \mathrm{P}<0.001$ vs. TNF- $\alpha$. (C) ALP activity detection following 7 days of osteogenic induction. ${ }^{* *} \mathrm{P}<0.01$ vs. control; ${ }^{\# \#} \mathrm{P}<0.01$ vs. TNF- $\alpha$. (D) mRNA expression levels of COL1 and RUNX2 were measured by RT-qPCR day 7 . ${ }^{* *} \mathrm{P}<0.01$ vs. control; ${ }^{\# \#} \mathrm{P}<0.01$ vs. TNF- $\alpha$. (E) ALP staining detection following osteogenic induction for 7 days (scale bar, $100 \mu \mathrm{m}$ ). (F) Alizarin Red staining detection following 21 days of osteogenic induction (scale bar, $100 \mu \mathrm{m}$ ). hPDLSCs, human periodontal ligament stem cells; Quer, quercetin; OIM, osteogenic induction medium; TNF- $\alpha$, tumor necrosis factor- $\alpha$; ALP, alkaline phosphatase.

diseases due to its extensive pharmacological properties. It has been shown that Quer can inhibit the IL-17-induced RANKL production and decrease IL-17-stimulated osteoclastogenesis in the bone destructive process (26). A previous study revealed that Quer decreased LPS-induced osteoclast formation, ligature-promoted periodontal inflammation and bone destruction with experimental periodontitis in rats (23). The present study found that Quer at concentrations of $<10 \mu \mathrm{M}$ did not exhibit 
A

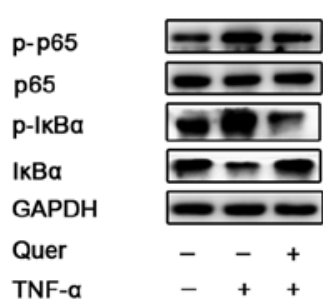

C

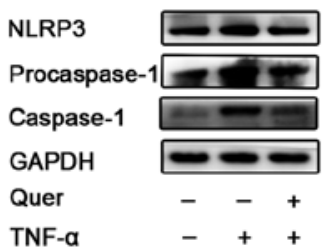

D

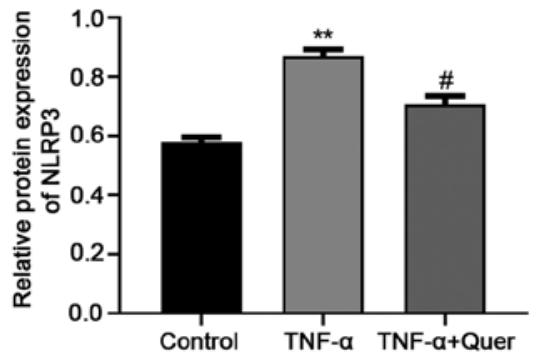

B

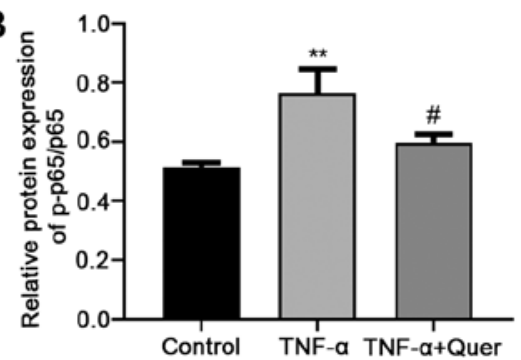

$\mathbf{E}$
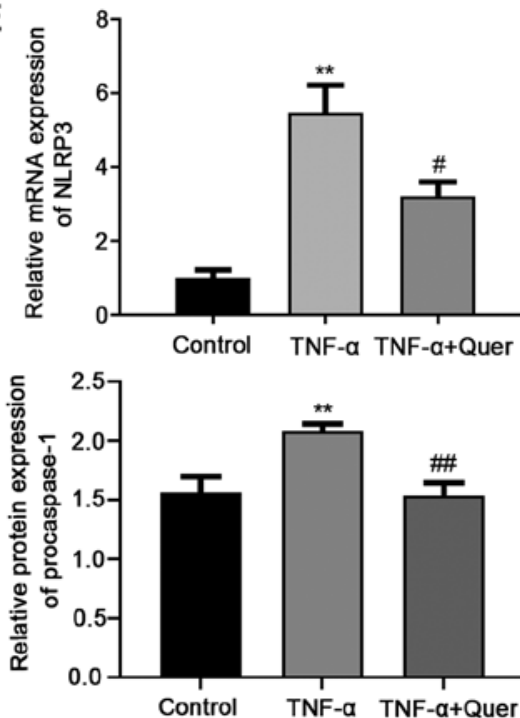
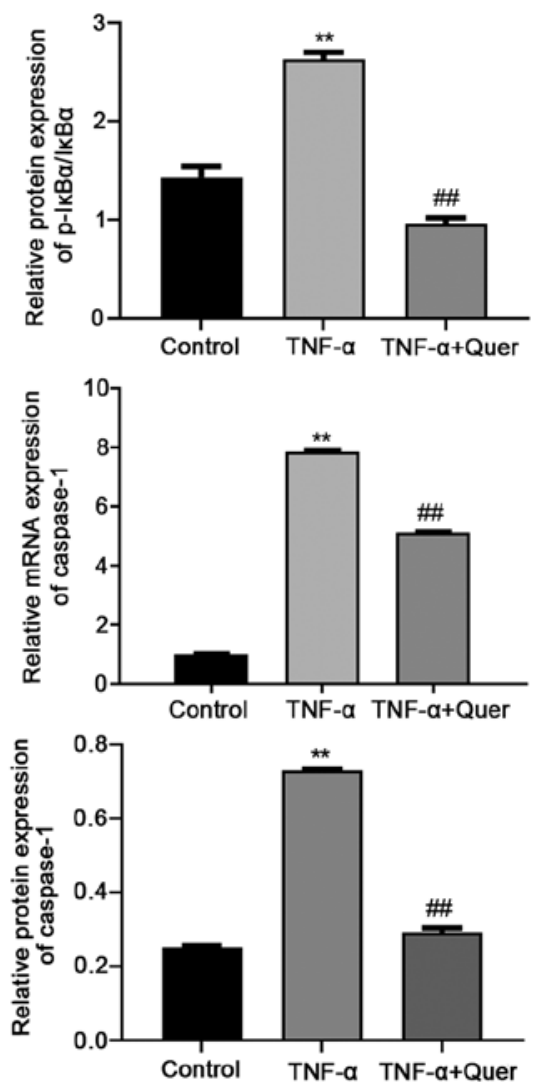

Figure 6. Effect of Quer on the activation of the NF- $\mathrm{B} / \mathrm{NLRP} 3$ pathway in TNF- $\alpha$-induced hPDLSCs. hPDLSCs were treated with $1 \mu \mathrm{M}$ Quer, 20 ng/ml

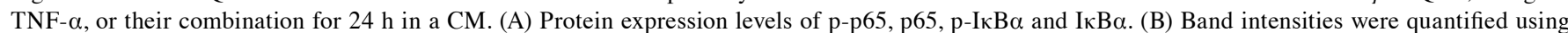
ImageJ software. ${ }^{* *} \mathrm{P}<0.01$ vs. control; ${ }^{\#} \mathrm{P}<0.05,{ }^{\# \#} \mathrm{P}<0.01$ vs. TNF- $\alpha$. (C) Protein expression levels of NLRP3, procaspase-1 and caspase-1. (D) Band intensities were quantified using the ImageJ software. ${ }^{* *} \mathrm{P}<0.01$ vs. control; ${ }^{\#} \mathrm{P}<0.05,{ }^{\# \#} \mathrm{P}<0.01$ vs. TNF- $\alpha$. (E) mRNA expression levels of NLRP3 and caspase-1. ${ }^{* *} \mathrm{P}<0.01$ vs. control; ${ }^{\#} \mathrm{P}<0.05$, ${ }^{\# \#} \mathrm{P}<0.01$ vs. TNF- $\alpha$. hPDLSCs, human periodontal ligament stem cells; Quer, quercetin; TNF- $\alpha$, tumor necrosis factor- $\alpha$; NLRP3, NOD-like receptor family pyrin domain-containing protein 3.

any cytotoxicity, but significantly prevented TNF- $\alpha$-induced osteogenic damage, particularly at the $1-10 \mu \mathrm{M}$ concentrations.

In periodontal disease, the upregulation of IL- $1 \beta$ and IL-6 is closely associated with the pathophysiology of periodontitis and can accelerate the degeneration of inflammatory periodontal tissues $(41,42)$. The present study used RT-qPCR to examine the mRNA expression levels of IL-1 $\beta$ and IL-6. Elevated IL-1 $\beta$ and IL-6 expression levels indicated that the model of inflammation was successfully mimicked by $\mathrm{TNF}-\alpha$ stimulation in vitro. Quer treatment decreased the TNF- $\alpha$-induced production of IL-1 $\beta$ and IL-6, and did not exert pro-inflammatory effects on hPDLSCs without TNF- $\alpha$. Moreover, the gene level of IL-1 $\beta$ following the different treatments suggested that the NLRP3 inflammasome may be activated in the process. Subsequently, the levels of the osteogenic differentiation representative genes and proteins, COL1, ALP and RUNX2, were determined by RT-qPCR and western blot analysis, respectively. The results demonstrated that Quer $(1 \mu \mathrm{M})$ significantly restored the osteogenic ability of the hPDLSCs which had been impaired by TNF- $\alpha$. Furthermore, ALP staining and the results of ARS were in accordance with the obtained mRNA and protein expression levels. It has been previously demonstrated that Quer can promote mouse BMMC proliferation and osteogenic ability (43). Similarly, the present study found that
Quer improved the osteogenic ability of hPDLSCs when compared to the control group without TNF- $\alpha$. These findings revealed that Quer antagonized the TNF- $\alpha$-induced inhibition of hPDLSC osteogenesis, which may be due to the suppression of inflammation and the pro-osteogenic effects on hPDLSCs.

The NF- $\kappa \mathrm{B}$ signaling pathway, as a significant downstream pathway of TNF- $\alpha$, is activated when TNF- $\alpha$ binds TNF receptor 1 (TNFR1) to inhibit osteogenesis-associated gene transcription and regulate osteogenic differentiation $(12,44,45)$. Studies have documented that various flavonoids, including Quer, can suppress LPS- or TNF- $\alpha$-induced key protein expression of the $\mathrm{NF}-\kappa \mathrm{B}$ signaling pathway $(46,47)$. These studies prompted us to determine whether the $\mathrm{NF}-\kappa \mathrm{B}$ pathway is a potential responsive mechanism through which Quer reverses the inhibitory osteogenic differentiation of TNF- $\alpha$ induced hPDLSCs. Consistent with previous studies $(46,47)$, the results of the present study demonstrated that the $1 \mu \mathrm{M}$ Quer concentration significantly inhibited the TNF- $\alpha$-induced phosphorylation of p65 and $\mathrm{I} \kappa \mathrm{B} \alpha$ in the hPDLSCs. Additionally, the NF- $\mathrm{B}$ signaling pathway is a priming signal for activating the NLRP3 inflammasome (14). It was also found that the activation of the $\mathrm{NF}-\kappa \mathrm{B}$ signaling pathway was not significantly influenced by the silencing of of NLRP3 in the TNF- $\alpha$-induced inflammatory microenvironment. Studies have revealed that Quer can attenuate diabetic encephalopathy 
A

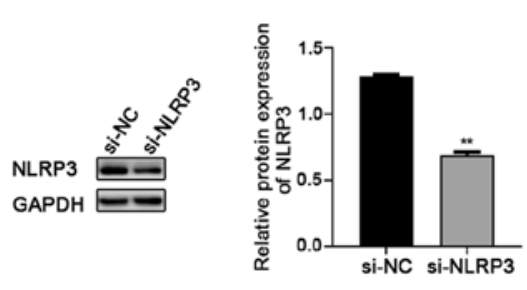

B

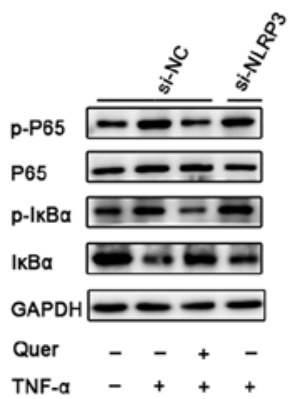

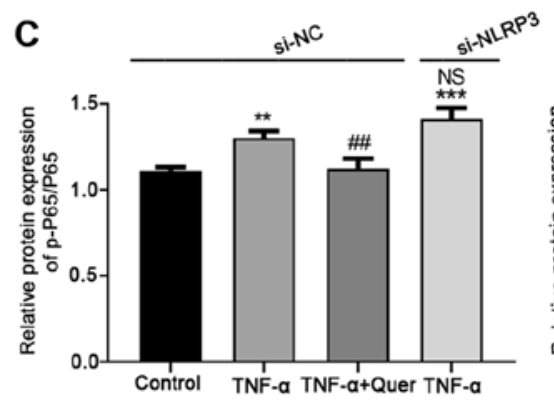
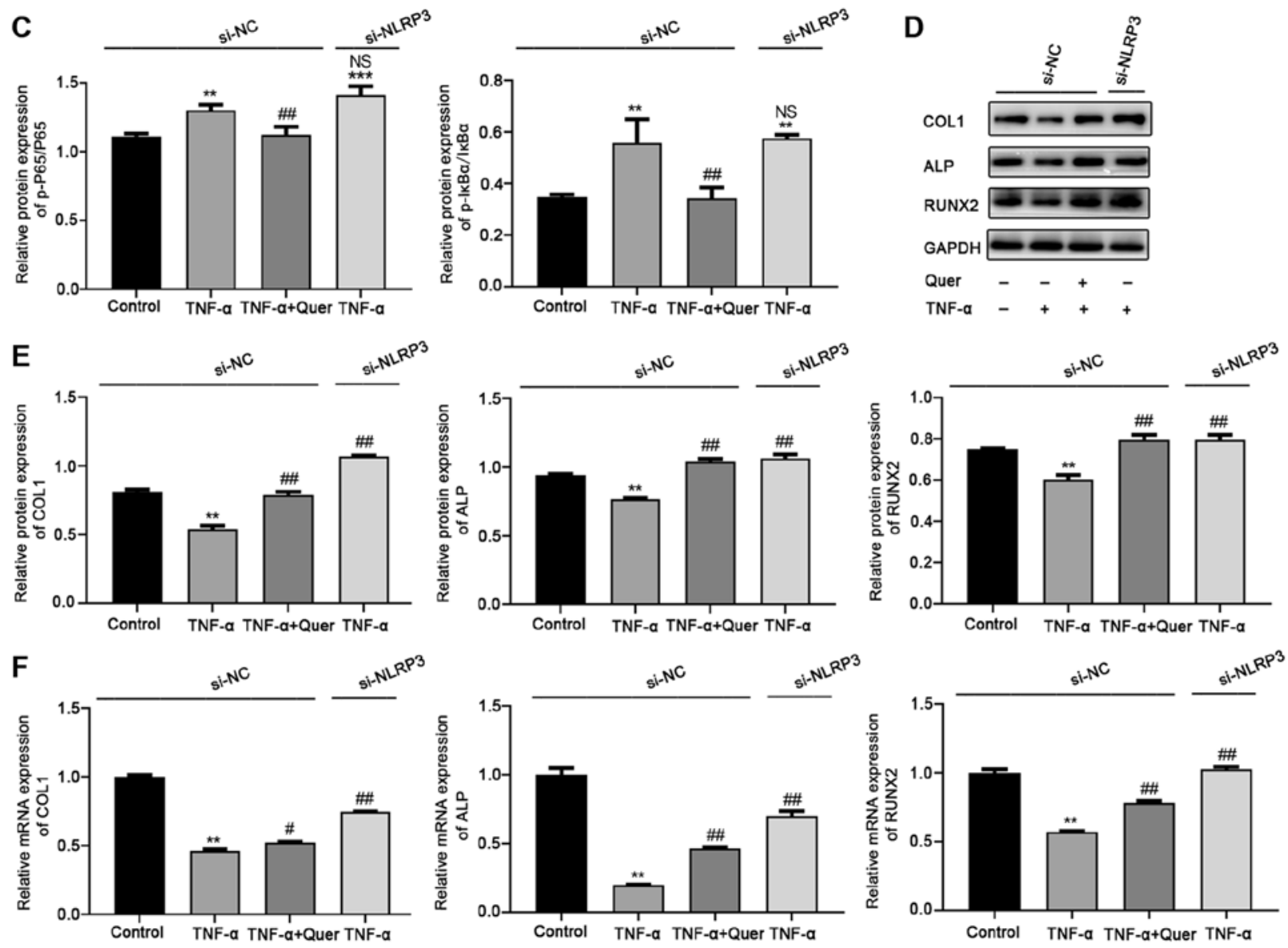

G

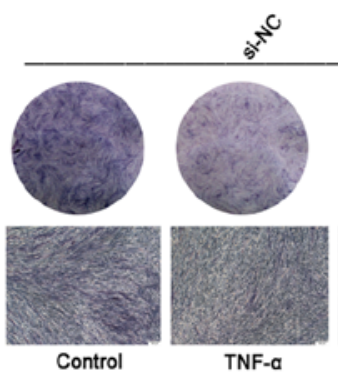

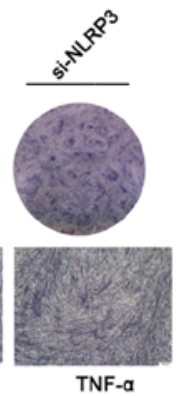

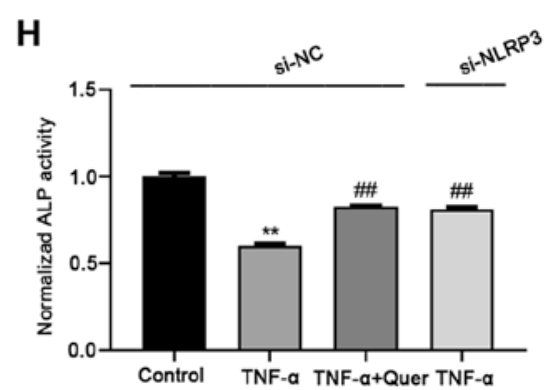

Figure 7. Antagonistic effect of si-NLRP 3 on the inhibition of the osteogenesis of hPDLSCs by TNF- $\alpha$. (A) Protein level of NLRP3 in hPDLSCs transfected with si-NLRP3 or si-NC was examined by western blot analysis. ${ }^{* *} \mathrm{P}<0.01$ vs. si-NC. (B) Protein levels of p-p65, p65, p-IкB $\alpha$ and IкB $\alpha$ were measured by western blot analysis. (C) Band intensities were quantified using ImageJ software. ${ }^{* *} \mathrm{P}<0.01,{ }^{* * * *} \mathrm{P}<0.001 \mathrm{vs}$. control + si-NC; ${ }^{\# \#} \mathrm{P}<0.01 \mathrm{vs}$. TNF- $\alpha+$ si-NC, NS (no significant difference) vs. TNF- $\alpha+$ si-NC. (D) Protein levels of COL1, ALP and RUNX2 on day 7 of osteogenic induction. (E) Band intensities were quantified using ImageJ software. ${ }^{* *} \mathrm{P}<0.01$ vs. control + si-NC; ${ }^{\# \#} \mathrm{P}<0.01$ vs. TNF- $\alpha+$ si-NC. (F) mRNA expression levels of COL1, ALP and RUNX2 following osteogenic induction for 7 days. ${ }^{* *} \mathrm{P}<0.01$ vs. control + si-NC; ${ }^{*} \mathrm{P}<0.05,{ }^{\# \#} \mathrm{P}<0.01$ vs. TNF- $\alpha+$ si-NC. (G) ALP staining following osteogenic induction for 7 days (scale bar, $100 \mu \mathrm{m}$ ). (H) ALP activity analysis on day 7 of osteogenic induction. ${ }^{* *} \mathrm{P}<0.01$ vs. control + si-NC; ${ }^{\# \#} \mathrm{P}<0.01 \mathrm{vs}$. TNF- $\alpha+s i-\mathrm{NC}$.

and protect against isoniazid-induced hepatotoxicity by suppressing the NLRP3 pathway $(30,48)$. Likewise, the present study determined that Quer downregulated the expression of
NLRP3 inflammasome-associated proteins and genes treated in the hPDLSCs stimulated with TNF- $\alpha$. Recent studies have revealed that NLRP3 inflammasome activation can suppress 
the osteogenesis of MSCs and can contribute to the estrogen deficiency-induced suppression of osteogenesis in ovariectomized mice $(18,19)$. However, few studies have demonstrated the effect of NLRP3 on the osteogenic differentiation of hPDLSCs stimulated with TNF- $\alpha$. The present study indicated that NLRP3 silencing reversed TNF- $\alpha$-induced osteogenic damage to hPDLSCs, similar to Quer treatment. Therefore, Quer treatment reversed the inhibition of osteogenic differentiation induced by TNF- $\alpha$, which may be associated with the inhibition of the NF- $\mathrm{B} / \mathrm{NLRP} 3$ inflammasome pathway.

In conclusion, the present study demonstrated that Quer reversed the suppression of the osteogenesis of hPDLSCs in an in vitro model of $\mathrm{TNF}-\alpha$-induced periodontitis by inhibiting the relative targets involved in the NF- $\mathrm{B} / \mathrm{NLRP} 3$ inflammasome pathway. These findings provide a basis for the use of the drug and stem cell combinations as an effective treatment agent for bone regeneration under inflammatory conditions.

\section{Acknowledgements}

The authors would like to thank the Director of Shandong Provincial Key Laboratory of Oral Tissue Regeneration for providing technical support with the study.

\section{Funding}

The present study was supported by the Construction Engineering Special Fund of Taishan Scholars (grant no. ts201511106) and the National Natural Science Foundation of China (grant no. 82071148).

\section{Availability of data and materials}

All data generated or analyzed during this study are included in this published article or are available from the corresponding author on reasonable request.

\section{Authors' contributions}

XX designed the study. WZ, LJ and BZ performed the experiments. JL, YX and YNW analyzed the experimental data. WZ wrote the article. All authors listed have read and approved the final manuscript.

\section{Ethics approval and consent to participate}

The present study was authorized by the Medical Ethical committee of School of Stomatology, Shandong University (protocol no. GR201806). Signed informed consent was provided from every participant according to the Declaration of Helsinki.

\section{Patient consent for publication}

Not applicable.

\section{Competing interests}

All authors declare that they have no competing interests.

\section{References}

1. Bartold PM and Van Dyke TE: Periodontitis: A host-mediated disruption of microbial homeostasis. Unlearning learned concepts. Periodontol 2000 62: 203-217, 2013.

2. Gao F, Chiu SM, Motan DA, Zhang Z, Chen L, Ji HL, Tse HF, Fu QL and Lian Q: Mesenchymal stem cells and immunomodulation: Current status and future prospects. Cell Death Dis 7: e2062, 2016.

3. Moradi SL, Golchin A, Hajishafieeha Z, Khani MM and Ardeshirylajimi A: Bone tissue engineering: Adult stem cells in combination with electrospun nanofibrous scaffolds. J Cell Physiol 233: 6509-6522, 2018.

4. Ouchi T and Nakagawa T: Mesenchymal stem cell-based tissue regeneration therapies for periodontitis. Regen Ther 14: 72-78, 2020.

5. Xia Y, Tang HN, Wu RX, Yu Y, Gao LN and Chen FM: Cell responses to conditioned media produced by patient-matched stem cells derived from healthy and inflamed periodontal ligament tissues. J Periodontol 87: e53-e63, 2016.

6. Bright R, Hynes K, Gronthos S and Bartold PM: Periodontal ligament-derived cells for periodontal regeneration in animal models: A systematic review. J Periodontal Res 50: 160-172, 2015.

7. Zhang Y, Xing Y, Jia L, Ji Y, Zhao B, Wen Y and Xu X: An in vitro comparative study of multisource derived human mesenchymal stem cells for bone tissue engineering. Stem Cells Dev 27: 1634-1645, 2018.

8. Trubiani O, Pizzicannella J, Caputi S, Marchisio M, Mazzon E, Paganelli R, Paganelli A and Diomede F: Periodontal ligament stem cells: Current knowledge and future perspectives. Stem Cells Dev 28: 995-1003, 2019.

9. Winning L, El Karim IA and Lundy FT: A Comparative analysis of the osteogenic potential of dental mesenchymal stem cells. Stem Cells Dev 28: 1050-1058, 2019.

10. Xu XY, He XT, Wang J, Li X, Xia Y, Tan YZ and Chen FM: Role of the $\mathrm{P} 2 \mathrm{X} 7$ receptor in inflammation-mediated changes in the osteogenesis of periodontal ligament stem cells. Cell Death Dis 10: 20, 2019.

11. Bartold PM,Cantley MD and Haynes DR: Mechanisms and control of pathologic bone loss in periodontitis. Periodontol 2000 53: 55-69, 2010.

12. Abbas S, Zhang YH, Clohisy JC and Abu-Amer Y: Tumor necrosis factor-alpha inhibits pre-osteoblast differentiation through its type-1 receptor. Cytokine 22: 33-41, 2003.

13. Huang H, Zhao N, Xu X, Xu Y, Li S, Zhang J and Yang P: Dose-specific effects of tumor necrosis factor alpha on osteogenic differentiation of mesenchymal stem cells. Cell Prolif 44: 420-427, 2011.

14. Bauernfeind FG, Horvath G, Stutz A, Alnemri ES, MacDonald K, Speert D, Fernandes-Alnemri T, Wu J, Monks BG, Fitzgerald KA, et al: Cutting edge: NF-kappaB activating pattern recognition and cytokine receptors license NLRP3 inflammasome activation by regulating NLRP3 expression. J Immunol 183: 787-791, 2009.

15. Guo H, Callaway JB and Ting JP: Inflammasomes: Mechanism of action, role in disease, and therapeutics. Nat Med 21: 677-687, 2015.

16. Schroder K and Tschopp J: The inflammasomes. Cell 140: 821-832, 2010.

17. Yi X, Zhang L, Lu W, Tan X, Yue J, Wang P, Xu W, Ye L and Huang D: The effect of NLRP inflammasome on the regulation of AGEs-induced inflammatory response in human periodontal ligament cells. J Periodontal Res 54: 681-689, 2019.

18. Wang L, Chen K, Wan X, Wang F, Guo Z and Mo Z: NLRP3 inflammasome activation in mesenchymal stem cells inhibits osteogenic differentiation and enhances adipogenic differentiation. Biochem Biophys Res Commun 484: 871-877, 2017.

19. Xu L, Zhang L, Wang Z, Li C, Li S, Li L, Fan Q and Zheng L: Melatonin suppresses estrogen deficiency-induced osteoporosis and promotes osteoblastogenesis by inactivating the NLRP3 inflammasome. Calcif Tissue Int 103: 400-410, 2018.

20. de Alencar JB, Zacarias JMV, Tsuneto PY, Souza VH, Silva COE, Visentainer JEL and Sell AM: Influence of inflammasome NLRP3, and IL1B and IL2 gene polymorphisms in periodontitis susceptibility. PLoS One 15: e0227905, 2020.

21. Isaza-Guzmán DM, Medina-Piedrahíta VM, Gutiérrez-Henao C and Tobón-Arroyave SI: Salivary levels of NLRP3 inflammasome-related proteins as potential biomarkers of periodontal clinical status. J Periodontol 88: 1329-1338, 2017. 
22. Li Y, Yao J, Han C, Yang J, Chaudhry MT, Wang S, Liu H and Yin Y: Quercetin, inflammation and immunity. Nutrients 8: 167, 2016.

23. Cheng WC, Huang RY, Chiang CY, Chen JK, Liu CH, Chu CL and Fu E: Ameliorative effect of quercetin on the destruction caused by experimental periodontitis in rats. J Periodontal Res 45: 788-795, 2010.

24. Yuan Z, Min J, Zhao Y, Cheng Q, Wang K, Lin S, Luo J and Liu H: Quercetin rescued TNF-alpha-induced impairments in bone marrow-derived mesenchymal stem cell osteogenesis and improved osteoporosis in rats. Am J Transl Res 10: 4313-4321, 2018.

25. Guo C, Yang RJ, Jang K, Zhou XL and Liu YZ: Protective effects of pretreatment with quercetin against lipopolysaccharide-induced apoptosis and the inhibition of osteoblast differentiation via the MAPK and Wnt/ $\beta$-Catenin pathways in MC3T3-E1 cells. Cell Physiol Biochem 43: 1547-1561, 2017.

26. Kim HR, Kim BM, Won JY, Lee KA, Ko HM, Kang YS, Lee SH and Kim KW: Quercetin, a plant polyphenol, has potential for the prevention of bone destruction in rheumatoid arthritis. J Med Food 22: 152-161, 2019.

27. Zendedel A, Johann S, Mehrabi S, Joghataei MT, Hassanzadeh G, Kipp $M$ and Beyer C: Activation and regulation of NLRP3 inflammasome by intrathecal application of SDF-1a in a spinal cord injury model. Mol Neurobiol 53: 3063-3075, 2016.

28. Jiang W, Huang Y, Han N, He F, Li M, Bian Z, Liu J, Sun T and Zhu L: Quercetin suppresses NLRP3 inflammasome activation and attenuates histopathology in a rat model of spinal cord injury. Spinal Cord 54: 592-596, 2016

29. Wu J, Xu X, Li Y, Kou J, Huang F, Liu B and Liu K: Quercetin, luteolin and epigallocatechin gallate alleviate TXNIP and NLRP3-mediated inflammation and apoptosis with regulation of AMPK in endothelial cells. Eur J Pharmacol 745: 59-68, 2014

30. Zhang Y, Qu X, Gao H, Zhai J, Tao L, Sun J, Song Y and Zhang J: Quercetin attenuates NLRP3 inflammasome activation and apoptosis to protect INH-induced liver injury via regulating SIRT1 pathway. Int Immunopharmacol 85: 106634, 2020.

31. Zhao B, Zhang $\mathrm{Y}$, Xiong $\mathrm{Y}$ and $\mathrm{Xu} \mathrm{X}$ : Rutin promotes the formation and osteogenic differentiation of human periodontal ligament stem cell sheets in vitro. Int J Mol Med 44: 2289-2297, 2019.

32. Livak KJ and Schmittgen TD: Analysis of relative gene expression data using real-time quantitative PCR and the 2(-Delta Delta C(T)) method. Methods 25: 402-408, 2001.

33. Bosshardt DD: The periodontal pocket: Pathogenesis, histopathology and consequences. Periodontol 2000 76: 43-50, 2018

34. Huang J, Liu L, Jin S, Zhang Y, Zhang L, Li S, Song A and Yang P: Proanthocyanidins promote osteogenic differentiation of human periodontal ligament fibroblasts in inflammatory environment via suppressing NF- $\kappa \mathrm{B}$ signal pathway. Inflammation 43 : 892-902, 2020

35. Yue H, Xu X, Liu Q, Li X, Xiao Y and Hu B: Effects of non-surgical periodontal therapy on systemic inflammation and metabolic markers in patients undergoing haemodialysis and/or peritoneal dialysis: A systematic review and meta-analysis. BMC Oral Health 20: 18, 2020.

36. Romero-Castro NS, Vázquez-Villamar M, Muñoz-Valle JF, Reyes-Fernández S, Serna-Radilla VO, García-Arellano S and Castro-Alarcón N: Relationship between TNF- $\alpha$, MMP-8, and MMP-9 levels in gingival crevicular fluid and the subgingival microbiota in periodontal disease. Odontology 108: 25-33, 2020
37. Ohori F, Kitaura H, Ogawa S, Shen WR, Qi J, Noguchi T, Marahleh A, Nara Y, Pramusita A and Mizoguchi I: IL-33 inhibits TNF- $\alpha$-induced osteoclastogenesis and bone resorption. Int J Mol Sci 21: 1130, 2020.

38. Tan J, Zhou L, Xue P, An Y, Luo L, Zhang R, Wu G, Wang Y, Zhu $\mathrm{H}$ and Wang Q: Tumor necrosis factor- $\alpha$ attenuates the osteogenic differentiation capacity of periodontal ligament stem cells by activating PERK signaling. J Periodontol 87: e159-e171, 2016.

39. Qin Z, Fang Z, Zhao L, Chen J, Li Y and Liu G: High dose of TNF- $\alpha$ suppressed osteogenic differentiation of human dental pulp stem cells by activating the Wnt/ $\beta$-catenin signaling. J Mol Histol 46: 409-420, 2015

40. Casado-Diaz A, Anter J, Dorado G and Quesada-Gómez JM: Effects of quercetin, a natural phenolic compound, in the differentiation of human mesenchymal stem cells (MSC) into adipocytes and osteoblasts. J Nutr Biochem 32: 151-162, 2016.

41. Noh MK, Jung M, Kim SH, Lee SR, Park KH, Kim DH, Kim HH and Park YG: Assessment of IL-6, IL-8 and TNF- $\alpha$ levels in the gingival tissue of patients with periodontitis. Exp Ther Med 6: 847-851, 2013

42. Marchesan JT: Inflammasomes as contributors to periodontal disease. J Periodontol 91 (Suppl 1): S6-S11, 2020.

43. Pang XG, Cong Y, Bao NR, Li YG and Zhao JN: Quercetin stimulates bone marrow mesenchymal stem cell differentiation through an estrogen receptor-mediated pathway. Biomed Res Int 2018: 4178021, 2018.

44. Chen X, Hu C, Wang G, Li L, Kong X, Ding Y and Jin Y: Nuclear factor- $\mathrm{\kappa B}$ modulates osteogenesis of periodontal ligament stem cells through competition with $\beta$-catenin signaling in inflammatory microenvironments. Cell Death Dis 4: e510, 2013.

45. Wang LM, Zhao N, Zhang J, Sun QF, Yang CZ and Yang PS: Tumor necrosis factor-alpha inhibits osteogenic differentiation of pre-osteoblasts by downregulation of EphB4 signaling via activated nuclear factor-kappaB signaling pathway. J Periodontal Res 53: 66-72, 2018.

46. Li T, Li F, Liu X, Liu J and Li D: Synergistic anti-inflammatory effects of quercetin and catechin via inhibiting activation of TLR4-MyD88-mediated NF- $\kappa$ B and MAPK signaling pathways. Phytother Res 33: 756-767, 2019.

47. Liu Y, Yu C, Ji K, Wang X, Li X, Xie H, Wang Y, Huang Y, Qi D and Fan H: Quercetin reduces TNF- $\alpha$-induced mesangial cell proliferation and inhibits PTX3 production: Involvement of NF-kB signaling pathway. Phytother Res 33: 2401-2408, 2019.

48. Hu T, Lu XY, Shi JJ, Liu XQ, Chen QB, Wang Q, Chen YB and Zhang SJ: Quercetin protects against diabetic encephalopathy via SIRT1/NLRP3 pathway in $\mathrm{db} / \mathrm{db}$ mice. J Cell Mol Med 24: 3449-3459, 2020.

This work is licensed under a Creative Commons Attribution-NonCommercial-NoDerivatives 4.0 International (CC BY-NC-ND 4.0) License. 